\title{
Fatores motivadores e facilitadores dos relacionamentos em redes: como os gestores públicos reconhecem esses fatores em dados governamentais abertos
}

\author{
Claudio Sonaglio Albano Doutorando em Administração. Universidade Federal do Pampa (UNIPAMPA) - Brasil. claudio.albano@gmail.com \\ Marcelo Henrique de Araujo Doutorando em Administração. Universidade de São Paulo (USP) - Brasil. marcelo.haraujo@gmail.com \\ Nicolau Reinhard Doutor em Administração. Universidade de São Paulo (USP) - Brasil. reinhard@fia.com.br
}

\begin{abstract}
RESUMO
Dados governamentais abertos objetivam a disponibilização de dados provenientes de instituições públicas na internet, de forma que esses possam ser reutilizáveis por terceiros. Tais iniciativas buscam atender novas demandas da sociedade, referentes ao aumento da transparência, maior participação na gestão dos recursos públicos, maior controle e qualidade dos serviços públicos, além de um aumento da responsabilização entre gestores públicos. Desta forma, pressupõem uma ampla participação e colaboração entre governo e sociedade, constituindo uma rede entre essas duas esferas. À luz da teoria de redes interorganizacionais, o presente artigo tem como objetivo compreender quais são os fatores motivacionais e facilitadores presentes em iniciativas de dados governamentais abertos. A fim de atender a esse objetivo, adotou-se uma estratégia metodológica qualitativa, por meio de entrevistas estruturadas, visando compreender sob a perspectiva dos gestores públicos de projeto de DGA os principais fatores motivadores e facilitadores presentes nestas iniciativas. Os resultados da pesquisa demonstram que os principais fatores motivadores de projetos de DGA são: (i) reciprocidade, (ii) eficiência e (iii) legitimidade. Em complemento, aspectos relacionados ao (i) poder, (ii) reputação, (iii) troca de informações e (iv) ativos específicos são caracterizados como principais fatores facilitadores de DGA na perspectiva dos gestores públicos. Tais resultados possibilitam uma melhor compreensão do relacionamento entre governo e sociedade a partir da ótica da teoria de redes interorganizacionais.
\end{abstract}

Palavras-Chave: Dados Governamentais Abertos. Fatores Motivadores e Facilitadores. Redes.

\section{Motivators and facilitators of relationships in networks: how public managers acknowledge these factors in open government data}

\begin{abstract}
Open Government Data (DGA) aim at the provision of data from public institutions on the Internet, so that these can be reusable by third parties. These initiatives aim to meet new demands of society for increased transparency, greater involvement in the management of public resources, greater control and quality of public services, and increased accountability among public officials. Thus, they assume a wide participation and collaboration between government and society, constituting a network between these two spheres. In light of the theory of interorganizational networks, this article aims to understand what the motivational factors and facilitators present in open government data initiatives are. In order to meet this goal, we adopted a qualitative methodological strategy through structured interviews, to understand, from the perspective of the DGA public managers project, the main motivators and facilitating factors present in these initiatives. The results of the research demonstrate that the main motivating factors of DGA projects are: (I) reciprocity, (II) efficiency, (III) legitimacy. In complementation, aspects related to (I) power, (II) reputation, (III) exchange of information, and (IV) specific assets are considered as facilitators of DGA in the perspective of public managers. These results allow for a better comprehension of the relationship between government and society
\end{abstract}

Keywords: Open Government Data. Motivating Factors and Facilitators. Network. 


\section{INTRODUÇÃO}

As organizações públicas (em especial os governos) estão sujeitas a novas exigências da sociedade, tais como: aumento da transparência na utilização dos recursos públicos, maior participação na gestão dos mesmos, maior controle sobre a qualidade dos serviços prestados, maior responsabilização dos gestores públicos, entre outras. A partir destas novas exigências políticas, econômicas e sociais, novas formas de gestão e de aproximação dos governos com a sociedade se fazem necessárias. Para fins deste trabalho serão considerados governos ou organizações públicas, toda e qualquer instituição que pertença a uma das três instâncias de governo no contexto brasileiro (federal, estadual e municipal), e/ou as organizações dos três poderes (executivo, legislativo e judiciário).

$\mathrm{Na}$ busca dessas novas formas de gestão, e especialmente visando maior aproximação com as novas exigências da sociedade, uma das possibilidades é a utilização de ferramentas tecnológicas. Com o advento de novas tecnologias, especialmente vinculadas à tecnologia da informação e comunicação (TIC) (com destaque para a internet), as organizações públicas estão viabilizando a oferta de uma variada gama de novos produtos e serviços à sociedade. Na última década a conjunção destes fatores viabilizou o surgimento de uma plataforma denominada Dados Governamentais Abertos (DGA).

Dados governamentais abertos consistem de iniciativas que visam à disponibilização de dados primários provenientes de instituições públicas na internet, de forma que esses possam ser reutilizáveis por terceiros. Portanto, é premissa básica de DGA que terceiros (em especial a sociedade) tenham livre acesso aos dados (respeitando as exigências legais), de forma que possam manipulá-los e gerar novas aplicações, produtos e/ou serviços (W3C, 2011).

Embora a disponibilização de dados governamentais abertos seja, razoavelmente, incipiente no Brasil, convém ressaltar que tais iniciativas não são recentes - especialmente na Europa e América do Norte, tendo nos últimos anos um apelo maior. Tais iniciativas estão sendo acompanhadas de uma maior normatização, legislação e outras formas de incentivo (OBAMA, 2009; KALAMPOKIS; TAMBOURIS, 2011; FIORETTI, 2011).

O tema assume importante papel no cenário público, pois aproximadamente uma centena de países já desenvolvem iniciativas com dados governamentais abertos. Logo, é plausível supor que novas exigências (políticas, legais, sociais e até mesmo tecnológicas) devam propiciar terreno fértil a essas iniciativas. Outro aspecto importante com relação ao tema, é que, talvez, pela primeira vez a sociedade possa fazer uso das informações públicas para fins econômicos, além das tradicionais iniciativas para promoção de maior cidadania e controle do governo.

Governos visualizam a utilização de DGA com a perspectiva de promover maior transparência, inovação e colaboração com os demais setores da sociedade. Tal fato é destacado 
por alguns autores, tais como Dawes e Helbig (2010) e Harrison et al. (2011), que enfatizam entre as premissas para a utilização de dados governamentais abertos, uma busca por maior transparência nas ações do governo e maior integração com a sociedade permitindo um acesso mais amplo aos dados criando novas oportunidades para os cidadãos, de forma que esses possam contribuir com experiência e perspectivas para a tomada de decisão dos governos.

Em iniciativas de DGA o objetivo principal não é o de oferecer produtos e/ou serviços (aplicativos) prontos para o uso da sociedade, mas sim possibilitar a essa o acesso à base de dados governamentais. Este fato condiciona o interesse da sociedade às ações do governo, pois este é o detentor das informações e o patrocinador (principal) destas iniciativas e deverá relacionar-se com todas as instâncias da sociedade para alcançar seus objetivos. Desta forma, se torna claro que nos projetos de dados governamentais abertos, deverá ser formada uma rede entre governo (por meio de seus diversos órgãos, níveis e segmentos) e a sociedade (por meio de seus múltiplos segmentos)

Alguns autores, entre os quais podemos citar Helbig et al. (2012), Dawes e Helbig (2012), Robinson et al. (2009), confirmam esta premissa que projetos de DGA pressupõem uma ampla participação e colaboração (relacionamento) entre governo e sociedade, em seus mais diversos níveis e segmentos. Autores como Prince, Jolías e Brys (2013), reafirmam que em projetos de dados governamentais abertos deverá ser formada uma rede entre o governo e a sociedade e que deve ser desenvolvido um ambiente que beneficie a todos, possibilitando o alcance dos respectivos objetivos, tanto dos setores da sociedade como dos governos.

Objetivando compreender como os governos, por intermédio de seus gestores de projeto de DGA, visualizam (ou reconhecem) fatores que podem impulsionar suas relações com a sociedade, nesse trabalho serão utilizadas as premissas da teoria das redes interorganizacionais. Esta teoria permite identificar como um participante de uma rede visualiza suas relações com os demais, quais motivações ou facilidades ele tem para participar desta rede. No intuito de delimitar o escopo desse trabalho, as referidas relações serão analisadas a partir dos fatores motivacionais e fatores facilitadores destes relacionamentos.

Pelo exposto até aqui se julga pertinente a questão de pesquisa colocada para esse trabalho, qual seja: Conhecer os fatores motivacionais e facilitadores dos relacionamentos no contexto de dados governamentais abertos pode oferecer melhores subsídios para os gestores públicos desenvolverem projetos de DGA? Outro fato que justifica o desenvolvimento desse trabalho é que segundo Helbig et al. (2012), os gestores públicos desejam efetivamente implementar e, principalmente, manter políticas de abertura de dados, fazendo uso dos recursos das TICs. Portanto, existe a necessidade de compreender melhor como e por que acontecem essas interações. Esse entendimento ainda não está totalmente disponível em guias, ferramentas, técnicas ou teorias para lidar com a abertura de dados no setor público. 
Autores como Gurstein (2011), confirmam a necessidade de mais estudos sobre o tema ao afirmar que ainda não foram encontrados estudos que documentassem os processos de abertura de bases de dados governamentais, tanto do ponto de vista tecnológico quanto do social, analisando o contexto e interesses envolvidos e fatores que podem influenciar os resultados finais dos projetos. Ainda segundo o mesmo autor, a literatura não oferece uma metodologia própria para auxiliar no desenvolvimento de tais processos, portanto, demonstrando que tal temática ainda é pouco explorada.

Para atender a questão de pesquisa, posta acima, o trabalho tem como principal objetivo identificar, conforme opinião de gestores públicos, quais os principais fatores motivacionais e facilitadores estão presentes em iniciativas de DGA. Entende-se que ao atingir esse objetivo, o trabalho contribui ao tema e seu contexto oferecendo maior e melhor conhecimento dos pressupostos da teoria das redes interorganizacionais, os quais podem servir como motivadores e facilitadores para melhor relacionamento entre governos e sociedade. $\mathrm{O}$ trabalho adotou uma estratégia metodológica de cunho qualitativo (SAMPIERI; COLLADO; LUCIO, 2013), por meio de entrevistas aplicadas a gestores de projetos de dados governamentais abertos.

Antes de prosseguir, é pertinente um esclarecimento do que é "um projeto de dados governamentais abertos" no contexto deste trabalho. Um projeto de DGA é considerado a iniciativa de um governo e todas as atividades desenvolvidas a partir de seu portal institucional (sítio da internet). Exemplo: o governo do estado de São Paulo (GOVERNO DO ESTADO DE SÃO PAULO, 2016) disponibiliza diversas bases de dados em formato de dados governamentais abertos em único site, para fins deste artigo essa iniciativa é considerada um projeto de DGA. Os documentos (portarias e outros) disponíveis no endereço acima citado confirmam esse entendimento, ou seja, conceituar estas iniciativas como "projetos de dados governamentais abertos".

Outro esclarecimento que se julga necessário é que durante este trabalho os termos dados e informações, serão utilizados com o mesmo sentido. Embora existam diferenças conceituais entre os mesmos, optamos pela orientação proposta por Santos (2009), que considera os verbetes como sinônimos (ou vocábulos intercambiáveis), assim os termos "dado" ou "informação" devem ser entendidos "como fatos sobre entidades que podem ter ou não significado para o sujeito que o manipula".

As demais seções deste artigo estão estruturadas da seguinte forma: na Seção 2 apresentase o referencial teórico pertinente ao trabalho, enfocando os princípios de dados governamentais abertos e redes interorganizacionais. Os procedimentos metodológicos adotados nesta investigação estão descritos na Seção 3. Na quarta seção apresentam-se os resultados e as análises. Finalmente, na Seção 5, são apresentadas as conclusões, limitações do trabalho e sugestões de possíveis trabalhos futuros. 


\section{REFERENCIAL TEÓRICO}

Nesta seção será realizada uma discussão sobre os temas principais deste trabalho: dados governamentais abertos e redes interorganizacionais. Conceitos, definições e os demais elementos norteadores que fundamentaram este trabalho estão descritos a seguir.

\subsection{Dados governamentais abertos (DGA)}

Dados governamentais abertos significam a disponibilização de informações na internet de forma que estas possam ser reutilizáveis por terceiros. É premissa básica de DGA que terceiros (em especial a sociedade) tenham livre acesso aos dados (respeitando as exigências legais) de forma que se possam manipulá-los e gerar novas aplicações - produtos e/ou serviços. Dados governamentais abertos estão alicerçados em três pilares: transparência, participação e colaboração.

Com relação à transparência, esta promove a responsabilidade de informar os cidadãos sobre o que o governo está fazendo e que ações serão realizadas. A participação permite aos cidadãos contribuir com suas ideias e competências, auxiliando os governos a elaborarem políticas mais eficazes e abrangentes. Essa colaboração aprimora a eficácia do governo, incentivando a cooperação entre a sociedade e os diferentes níveis de governo (MAZONI, 2011).

Segundo Open Knowledge Foundation (OKF, 2016) dados governamentais abertos são dados disponíveis de forma que qualquer pessoa possa fazer uso livremente, reutilizar e distribuir (redistribuir), estando sujeito a, no máximo, exigência de creditar autoria e compartilhar pela licença. Esta condição geralmente é satisfeita pela publicação dos dados em formato aberto e sob uma licença aberta. Desta forma, governo aberto e dados governamentais abertos são conceitos utilizados seguidamente como sinônimos, embora não haja consenso. Alguns autores (sendo esta também a premissa deste trabalho) entendem que existem diferenças entre estes conceitos e respectivas finalidades. Governo aberto é um conceito mais amplo que dados abertos, pois significa a disponibilização de todas as informações (em qualquer formato), que estejam sob a responsabilidade de um governo (HEATH; BIZER, 2011).

Outra definição para dados governamentais abertos pode ser encontrada em Sapena, Peset e Benavent (2011), segundo estes autores dados abertos são dados disponibilizados em formatos pré-determinados de forma que possam ser utilizados (reutilizados) para fornecer serviços e aplicativos úteis para a sociedade, podendo, portanto, ser disponibilizados e usados em qualquer dispositivo tecnológico. Diniz (2010) afirma que a disponibilização de DGA permite que as informações sejam utilizadas da maneira e conveniência dos interessados, visando agregar mais valor aos dados. Entretanto, o mesmo autor relata que será inócua a disponibilização de dados que não forem do interesse da sociedade. 
Os governos também devem estar atentos à capacidade de entendimento desses dados pela sociedade. Muitos dados governamentais, se não a grande maioria, são de difícil entendimento para usuários leigos. Pode-se imaginar um cidadão sem formação adequada, acessando sítios de DGA com dados sobre receitas orçadas, receitas realizadas, despesas orçadas, suplementação de receitas e despesas e outras terminologias próprias do contexto da gestão pública. Esta preocupação fica evidente em W3C (2009), quando relata que uma das preocupações dos governos com dados abertos deve ser a de promover a capacitação da sociedade para o uso das tecnologias de dados abertos.

Assim, fica evidente que para uma eficiente utilização da plataforma de dados governamentais abertos, além dos esforços governamentais para disponibilizar tais dados são necessárias iniciativas junto à sociedade para que esta se sinta motivada e capacitada para fazer uma melhor utilização destes dados. Somente assim pode-se alcançar de forma eficiente toda a potencialidade e vantagens de projetos de dados abertos.

Entre as vantagens tanto para governo como para a sociedade, pode-se citar: estímulo ao acompanhamento de políticas públicas, empoderamento de novos atores, melhor suporte à tomada de decisão do governo e do cidadão, facilitar o uso de informações intra e entre esferas de governo, novos mercados para área de TIC e finalmente estímulo à inovação e colaboração (JANSSEN; CHARALABIDIS; ZUIDERWIJK, 2012).

\subsection{Redes interorganizacionais}

Um projeto de dados governamentais abertos é estabelecido pelo (por um determinado) governo, mas pode envolver diversos órgãos/níveis/segmentos dentro de um mesmo governo ou de diversos governos, caso de portais que aceitam dados de outros governos. Exemplo o portal de dados do Governo Federal Brasileiro, que disponibiliza dados de outros governos (estaduais, municipais, entre outras esferas).

Desta forma são desenvolvidas diversas relações entre: governos $X$ governos, governos $X$ sociedade e sociedade $X$ sociedade. Realizar análise das relações entre organizações é uma tarefa complexa, especialmente em ambientes de relações heterogêneas (organizações públicas $X$ organizações privadas). A complexidade torna-se ainda maior quando cada organização participante tem interesses e vínculos diversos e pode participar simultaneamente de diversas redes interorganizacionais. Esta é uma das características de relacionamentos interorganizacionais que devem ser dinâmicos, pois mudam com o tempo e tem como principal objetivo promover a interação entre os atores participantes da rede.

Para Balestrin e Vargas (2002), é pertinente o interesse pelo estudo das relações interorganizacionais. Este interesse é justificado por diversos fatores, tais como: novas formas de 
organizações e o impacto causado pela adoção das novas TICs, que viabiliza maior interação entre as organizações.

Segundo Marcon e Moinet (2001), a institucionalização de uma rede colaborativa depende da combinação e ocorrência de três elementos fundamentais para que essas possam, de fato, acontecer no mundo real das organizações, para isto devem existir: a) recursos disponíveis ou objetos para a troca (informações, conhecimentos e insumos), que constituem a base de uma rede colaborativa; b) infraestrutura informacional e procedural que designa o conjunto de regras de funcionamento e ética, que devem ser observados entre usuários da rede; e c) infraestrutura física e tecnológica, que compõe os meios práticos de ação, tais como orçamento, local, material, comunicação, conexão e equipamentos tecnológicos, entre outros.

Pelas características de dados governamentais abertos, expostas no tópico anterior, nota-se que estes projetos possuem as características citadas pelos autores acima como necessárias para configurar uma rede colaborativa. Diversas são as análises e abordagens possíveis acerca de redes interorganizacionais, pode-se citar: vantagens que as organizações buscam ao participar de redes, configuração dos arranjos interorganizacionais, formas e mecanismos de coordenação, abordagem dos relacionamentos interorganizacionais e fatores que podem sustentar (apoiar) esses relacionamentos.

Importante identificar que fatores sustentam as relações que se estabelecem em redes interorganizacionais. Neste sentido basicamente duas grandes vertentes (aspectos) são apontadas como capazes de sustentarem essas relações, são os aspectos motivadores (ou motivacionais) e os aspectos facilitadores. Projetos de DGA são, relativamente, recentes em especial no contexto brasileiro. O governo federal brasileiro começou seus primeiros movimentos neste sentido ao final da década passada, sendo seguido por outros governos. Assim, justifica-se a busca por identificar que fatores podem motivar e (ou) facilitar estas iniciativas. 
Quadro 01 - Fatores motivacionais em redes interorganizacionais.

\begin{tabular}{|c|l|}
\hline Fator & \multicolumn{1}{|c|}{ Descrição - Características } \\
\hline Necessidade & $\begin{array}{l}\text { Quando as organizações têm necessidade em interagir com as demais, } \\
\text { sejam por razões comerciais, legais ou de outras fontes. }\end{array}$ \\
\hline Assimetria & $\begin{array}{l}\text { Quando uma organização exerce poder sobre as demais, especialmente } \\
\text { quando outras dependem desta organização. O poder é exercido através } \\
\text { de capacidades competitivas ou propriedades de recursos. }\end{array}$ \\
\hline Reciprocidade & $\begin{array}{l}\text { Está relacionada com a cooperação e/ou colaboração entre as } \\
\text { organizações como forma de alcançarem objetivos comuns. }\end{array}$ \\
\hline Eficiência & $\begin{array}{l}\text { Quando duas ou mais organizações cooperam em busca de maior } \\
\text { eficiência. }\end{array}$ \\
\hline Legtabilidade & $\begin{array}{l}\text { Em ambientes de constante incerteza as organizações podem buscar } \\
\text { maior participação em redes como forma de buscar e manter maior } \\
\text { estabilidade e previsibilidade. }\end{array}$ \\
\hline $\begin{array}{l}\text { Quando uma organização busca legitimar sua atuação através de seus } \\
\text { parceiros, ou seja, pela reputação destes. Outra forma de legitimar sua } \\
\text { participação no mercado é através da utilização de normas e } \\
\text { procedimentos aceitos como suporte e/ou condutoras de processos } \\
\text { eficientes. }\end{array}$ \\
\hline
\end{tabular}

Fonte: Adaptado de Oliver (1990).

No Quadro 01 estão descritos os fatores motivacionais que podem influenciar as interações (relações) em redes interorganizacionais que serão considerados para as análises das entrevistas neste trabalho.

Quadro 02 - Fatores facilitadores em redes interorganizacionais.

\begin{tabular}{|c|l|}
\hline Fator & \multicolumn{1}{c|}{ Descrição - Características } \\
\hline Poder & $\begin{array}{l}\text { Quando uma organização participa de uma rede e/ou relacionamento, } \\
\text { deve estar consciente de seu efetivo posicionamento nesta rede. O poder } \\
\text { da organização pode ser mensurado por alguns fatores, tais como sua } \\
\text { independência em relação a seus fornecedores e seu posicionamento } \\
\text { estratégico na rede. }\end{array}$ \\
\hline Governança & $\begin{array}{l}\text { As organizações participantes buscam resolver eventuais conflitos que } \\
\text { possam surgir, especialmente em ambientes complexos. }\end{array}$ \\
\hline Confiança & $\begin{array}{l}\text { A confiança é necessária quando o risco, a vulnerabilidade do negócio, é } \\
\text { maior que os ganhos econômicos advindos do relacionamento. A } \\
\text { confiança está diretamente relacionada com as expectativas com relação } \\
\text { às ações dos parceiros. }\end{array}$ \\
\hline Troca de & $\begin{array}{l}\text { Reputação é estabelecida através de uma série de comportamentos } \\
\text { passados, quanto mais bem sucedidas as atitudes melhor a reputação e } \\
\text { até mesmo pela procura de determinados parceiros. }\end{array}$ \\
\hline informações & $\begin{array}{l}\text { Fator fundamental para duas ou mais organizações estabelecerem um } \\
\text { relacionamento. Uma eficiente troca de informações facilita outros } \\
\text { aspectos como a confiança e governança. Este processo ocorrendo de } \\
\text { forma eficiente também proporciona melhor utilização de recursos e } \\
\text { acesso a mercados e demais parceiros. }\end{array}$ \\
\hline Ativos específicos & $\begin{array}{l}\text { São os investimentos realizados pelos parceiros para a concretização da } \\
\text { mesma. Estes investimentos podem ser em tecnologia, processos, } \\
\text { recursos humanos e outros. Quanto mais um parceiro realiza } \\
\text { investimentos em uma relação, mais ele incentiva os demais parceiros, } \\
\text { facilitando o desenvolvimento da mesma. }\end{array}$ \\
\hline
\end{tabular}

Fonte: Adaptado de Cox (1999, 2004), Williamson (2005), Parkhe (1998), Grandori e Soda (1995). 
No Quadro 02 estão descritos os fatores facilitadores que podem influenciar as interações (relações) em redes interorganizacionais que serão considerados para as análises das entrevistas neste trabalho.

Entende-se pertinente a utilização das redes interorganizacionais neste trabalho pela sua importância na nova economia no processo de criação de valor. Porter (1996), já reconhecia que a vantagem competitiva está em conectar e não simplesmente colecionar atividades que sustentem valor, esta afirmação enfatiza a importância da formação das redes no processo de criação (ou cocriação) de valor. Projetos de DGA apresentam características aderentes às redes interorganizacionais, especialmente pelas premissas da participação e colaboração, premissas que geram um ambiente propício para a cocriação de valor.

\section{PROCEDIMENTOS METODOLÓGICOS}

A estratégia de pesquisa é exploratória, segundo Hair Jr. et al. (2005), estudos exploratórios são adequados para ampliar o conhecimento do pesquisador sobre fenômeno pouco conhecido e quando o pesquisador não espera obter uma resposta definitiva para o problema proposto. Recomenda-se este delineamento de pesquisa quando o tema escolhido é pouco conhecido e/ou pouco explorado ou se pretende abordar novos enfoques. O contexto do trabalho, dados governamentais abertos, justifica a escolha da estratégia de pesquisa, pois o tema é relativamente precoce no contexto brasileiro.

A estratégia metodológica adotada é de natureza qualitativa, segundo Sampieri, Collado e Lucio (2013) esta abordagem pode ser associada com os estudos exploratórios, sendo possível a correlação entre dois ou mais conceitos, categorias ou variáveis, ainda que não se meçam as relações, nem se estabeleçam numericamente sua magnitude. Trabalhos qualitativos são mais indicados quando se procura descrever a complexidade de determinado problema ou processos dinâmicos, como é o caso das relações que devem ser estabelecidas em projetos de dados governamentais abertos. A coleta de dados foi realizada por meio de entrevistas estruturadas, isto é, com questões pré-determinadas, essa estratégia de coleta de dados facilita a análise e interpretação das respostas, pois as questões estão em ordem e formato pré-determinados. A coleta de dados foi de corte transversal, uma vez que os dados foram coletados em um dado momento no tempo, e não há intenção de avaliar/monitorar suas variações no decorrer do tempo (SAMPIERI; COLLADO; LUCIO, 2006).

As entrevistas foram compostas de questões que visavam instigar os entrevistados sobre os aspectos que pudessem apoiar as respostas aos objetivos do trabalho. A primeira parte da entrevista continha questões que visavam identificar o perfil do entrevistado e seu local de atuação (organização pública). Posteriormente, as questões visavam identificar quais as motivações e/ou 
objetivos das organizações ao promoverem seus projetos de dados governamentais abertos. As demais questões abordavam tópicos referentes às vantagens que as organizações buscam ao participar das redes interorganizacionais, bem como quais fatores, agentes ou organizações podem atuar como motivadores ou facilitadores das iniciativas de DGA sob a ótica das redes interorganizacionais.

Em trabalhos qualitativos, a etapa de análise dos dados não é uma tarefa fácil, pois o pesquisador estará trabalhando com textos e não com números, nesse trabalho a análise dos dados foi realizada por intermédio das premissas da análise de conteúdo. Para Vergara (2005) a análise de conteúdo constitui uma técnica que possibilita a identificação do que está sendo dito (ou sendo expresso) a respeito de determinado conteúdo.

Conforme Bardin (2009) uma das formas de operacionalizar a análise de conteúdo, é realizar a categorização dos textos brutos advindos da coleta de dados. Esta categorização pode ser realizada a priori, como foi nesse trabalho. A categorização a priori deve ser construída a partir de uma fundamentação teórica, assim as categorias foram criadas, conforme os pressupostos teóricos que suportam o desenvolvimento do trabalho (premissas das redes interorganizacionais), visando atender aos objetivos propostos.

Quadro 03 - Categorias definidas para análise dos dados

\begin{tabular}{|c|l|}
\hline Categorias & \multicolumn{1}{c|}{ Características de cada categoria } \\
\hline $\begin{array}{c}\text { Perfil do entrevistado e forma } \\
\text { de atuação }\end{array}$ & $\begin{array}{l}\text { Questões relacionadas à formação acadêmica, profissional e } \\
\text { atuação do entrevistado. }\end{array}$ \\
\hline $\begin{array}{c}\text { Fatores motivacionais. } \\
\text { Redes interorganizacionais. } \\
\text { Quadro 01. }\end{array}$ & $\begin{array}{l}\text { Questões relacionadas aos seguintes fatores motivacionais: } \\
\text { (i) necessidade, (ii) assimetria, (iii) reciprocidade, (iv) } \\
\text { eficiência, (v) estabilidade e (vii) legitimação. }\end{array}$ \\
\hline $\begin{array}{c}\text { Fatores facilitadores. } \\
\text { Redes interorganizacionais. } \\
\text { Quadro 02. }\end{array}$ & $\begin{array}{l}\text { Questões relacionadas aos seguintes fatores facilitadores: (i) } \\
\text { poder, (ii) governança, (iii) confiança, (iv) reputação, (v) troca } \\
\text { de informações e (vi) ativos específicos. }\end{array}$ \\
\hline
\end{tabular}

As categorias devem ser válidas e a classificação de qualquer elemento deve ser consistente. Uma categorização válida deve ser significativa em relação aos conteúdos dos materiais que estão sendo analisados e de forma coerente com os objetivos do trabalho (no caso, desta etapa do trabalho). $\mathrm{Na}$ análise dos dados, se buscou identificar a ocorrência de citações ou referências as categorias previamente estabelecidas, conforme indicado no Quadro 3 (CRESWELL, 2011).

Uma preocupação quando se realiza entrevistas é com relação: quantas entrevistas fazer? Quem deve ser entrevistado? Diversos autores, entre os quais os já citados neste tópico (Seção 3), afirmam que em pesquisas qualitativas, as entrevistas não precisam ser numerosas, mas devem ser representativas. É importante a escolha dos entrevistados, esses devem ser capazes de fornecer as 
informações que o pesquisador busca. Assim, a seguir realiza-se uma descrição do processo de seleção dos entrevistados e justifica-se a pertinência da escolha dos entrevistados.

Conforme já relatado anteriormente para fins deste trabalho é realizada uma clara distinção entre governo aberto e dados governamentais abertos. Também foi colocado um conceito do que se entende nesse trabalho por "projeto de dados governamentais abertos", desta forma abaixo se descreve a seleção dos entrevistados. Para "mapear" os projetos de dados governamentais abertos existentes no Brasil, utilizou-se a ferramenta de pesquisa Google. Através desta, foram realizadas pesquisas utilizando algumas palavras chaves que foram as seguintes: "portal de dados abertos", "portal de governo aberto", "portal da transparência" e "www.acessoainformacao.XX.gov.br", onde XX foi substituído por todas as abreviaturas dos estados (unidades da federação) brasileiros.

Essas buscas foram realizadas em novembro de 2012, na qual foram encontrados "projetos de dados abertos" nas seguintes organizações públicas: um governo Estadual da região sul, um governo Estadual da região sudeste, um governo Estadual da região nordeste, um município no Estado do Rio Grande do Sul, um município no Estado do Paraná, portal de dados abertos do Governo Federal, uma Câmara de Vereadores de uma capital da região sudeste, Câmara Federal, Senado Federal, um Tribunal de Contas de um Estado da região sul e um Tribunal de Contas de um Estado da região nordeste.

Os projetos e respectivos respondentes serão mantidos no anonimato, conforme termos consentidos quando das entrevistas, embora no parágrafo acima se tenha citado explicitamente a Câmara Federal e Senado Federal (que identifica estas duas organizações públicas). Foram encontrados 11 "projetos de dados governamentais abertos". Em seguida, foram realizados contatos com todos os responsáveis por estes projetos, conforme indicado em seus respectivos sítios (páginas na internet). Ao realizar este contato, dois sítios (projetos) não retornaram respostas. Dos nove que retornaram respostas, dois afirmaram que o projeto de dados abertos não tinha um profissional que pudesse responder pelo mesmo. Assim restaram sete possíveis respondentes, durante a fase de entrevistas obteve-se sucesso (contato, entrevistas e respostas) válidas com seis respondentes. Todos os respondentes eram (ou são) servidores públicos, ou seja, membros dos governos e responsáveis por projetos de DGA.

As entrevistas foram realizadas durante os meses de janeiro, fevereiro e março de 2013, registradas em formulários enviados/respondidos via correio eletrônico ou pessoalmente. A maior parte das entrevistas foi realizada por meio de correio eletrônico, exceto uma das entrevistas que ocorreu pessoalmente, tendo seu conteúdo transcrito e validado com o entrevistado, no intuito de garantir a exatidão dos dados coletados. Dos seis respondentes, quatro atuam em governos que começaram seus projetos de DGA entre os anos de 2011 e 2012, os outros dois iniciaram seus projetos entre os anos de 2009 e 2010. Outros três governos com projeto de DGA, que não retornaram os contatos de forma a viabilizar a entrevista, esses iniciaram seus projetos de dados 
governamentais abertos no ano de 2012, conforme informações em suas páginas na internet. Esses fatos reforçam a questão da precocidade desses projetos no cenário brasileiro.

\section{RESULTADOS E ANÁLISES}

Neste capítulo estão descritos os principais achados deste trabalho. Para esta finalidade optou-se por separar os aspectos motivadores, abordados em primeiro lugar e, posteriormente, os aspectos facilitadores. Também se optou por transcrever as respostas que identificam (apontam) claramente para os aspectos motivadores e facilitadores. Quando um fator foi citado por mais de um entrevistado, optou-se por colocar estas citações em quadros, como forma de facilitar a visualização.

\subsection{Fatores motivadores}

Conforme já demonstrado neste trabalho, projetos de dados DGA são recentes no Brasil. Em termos quantitativos estes também são um número reduzido, desta forma torna-se interessante identificar na visão de seus gestores quais fatores podem motivar os demais setores da sociedade e até mesmo os próprios governos a participarem destes projetos. O termo "participarem" é no sentido de que a sociedade e até mesmo os governos utilizem as informações disponíveis nestes projetos. Os aspectos motivacionais utilizados neste trabalho são os descritos por Oliver (1990), conforme Quadro 01.

O fator motivador necessidade, tem como uma de suas premissas o atendimento às necessidades legais. No Brasil existe uma lei - de número 12.527 de 18 de novembro de 2011, que entrou em vigor em 16 de maio de 2012 (Lei de Acesso à Informação) - que determina que as informações públicas estejam disponibilizadas em formato aberto. Entretanto, apenas um entrevistado respondeu que este foi um fator motivador para os projetos de dados governamentais abertos. A seguir transcrevemos o trecho da resposta que identifica esta assertiva: “[...] que veio a se transformar na Lei de Acesso à Informação (Lei 12.527 de 2011), iniciamos o projeto de dados abertos, para atender os requisitos da lei".

Durante as análises das entrevistas foram encontradas referências ao fator motivador assimetria. Dados governamentais abertos existem para disponibilizar informações, que o governo (essencialmente ele) detém. Isto configura uma possível característica do fator motivador assimetria (Quadro 01), qual seja "quando o poder é exercido através de capacidades competitivas ou propriedades de recursos", neste caso a propriedade seria do recurso "informação". Optou-se por demonstrar as referências a este fator motivador juntamente com o fator facilitador poder, pois em ambos os fatores os entrevistados destacaram o fato dos governos deterem um recurso básico e estratégico para esta rede, ou seja, a informação. Quanto ao fator motivador reciprocidade, este abrange entre suas características uma das premissas de DGA, que é a colaboração. Diversos 
entrevistados reconheceram essa capacidade de colaboração em suas respostas, estando essas expostas no Quadro 04.

Quadro 04 - Análises do fator reciprocidade.

\begin{tabular}{|c|c|}
\hline $\begin{array}{l}\text { Fator motivador } \\
\text { reciprocidade }\end{array}$ & Respostas que reconhecem o fator motivador reciprocidade \\
\hline $\begin{array}{l}\text { Premissa: Está } \\
\text { relacionada com a } \\
\text { cooperação e/ou } \\
\text { colaboração entre as } \\
\text { organizações como } \\
\text { forma de } \\
\text { alcançarem } \\
\text { objetivos comuns. }\end{array}$ & $\begin{array}{l}\text { "Ver a sociedade civil gerando produtos de valor, ou seja, informações } \\
\text { úteis, com base nos dados disponibilizados"; } \\
\text { "Tornar a informação disponível vai ajudar os próprios órgãos de governo } \\
\text { a terem acesso à base de dados de outros órgãos, então, a abertura dos } \\
\text { dados é benéfica para dentro do governo e para a relação entre o } \\
\text { governo e a sociedade"; } \\
\text { "Tripé formado por: Governo/dados abertos X Crowdsourcing X Redes } \\
\text { Sociais, pode contribuir positivamente para o desenvolvimento de } \\
\text { produtos/serviços/aplicações na sociedade"; } \\
\text { "Projetos de dados abertos contribuirão para geração de conhecimento } \\
\text { de forma colaborativa" e; } \\
\text { "Atender a uma sociedade mais colaborativa, que tem demandas, que } \\
\text { precisam ser atendidas rapidamente". }\end{array}$ \\
\hline
\end{tabular}

Diversos entrevistados em suas respostas reconheceram a existência do fator motivador eficiência. Os excertos dessas respostas estão expostos no quadro 05.

Quadro 05 - Análises do fator eficiência.

\begin{tabular}{|c|c|}
\hline $\begin{array}{l}\text { Fator motivador } \\
\text { eficiência }\end{array}$ & Respostas que reconhecem o fator motivador eficiência \\
\hline $\begin{array}{l}\text { Premissa: Quando } \\
\text { duas ou mais } \\
\text { organizações } \\
\text { cooperam em busca } \\
\text { de maior eficiência. }\end{array}$ & $\begin{array}{l}\text { "Expectativa de ver a sociedade exigir mais do governo ao observar as } \\
\text { informações úteis geradas a partir dos dados abertos"; } \\
\text { "Quando se fala de dados abertos, entendemos que governo não é um } \\
\text { governo único. Tem instâncias de governo municipal, estadual e federal } \\
\text { e numa mesma instância existem os poderes Executivo, Legislativo e } \\
\text { Judiciário, com suas bases de dados nem sempre interoperáveis. Essa } \\
\text { disponibilidade (dados abertos) vai fazer com que essas coisas se } \\
\text { acelerem, porque as integrações serão mais viáveis porque os dados } \\
\text { serão cruzados"; } \\
\text { "Análise desses dados, potencializada pela capacidade de cruzá-los com } \\
\text { dados oferecidos por outras entidades, oferecerá à sociedade uma } \\
\text { grande capacidade de fiscalizar e interferir nas ações governamentais. } \\
\text { Como consequência, o governo terá que melhorar seus processos e } \\
\text { serviços"; } \\
\text { "Esperamos que a sociedade possa contribuir com a fiscalização e com o } \\
\text { aprimoramento dos processos internos". }\end{array}$ \\
\hline
\end{tabular}

Fonte: Dados da pesquisa (2016). 
Pode-se observar que os respondentes identificam em DGA elementos motivadores caracterizados como busca da eficiência, ou seja, as organizações esperam obter maior eficiência a partir dessa possibilidade de interação, através dos projetos de dados governamentais abertos. Em relação ao fator motivador estabilidade não se encontrou entre as respostas nenhuma referência as suas características, expostas no Quadro 01. De outra parte diversos entrevistados em suas respostas reconheceram a existência do fator motivador legitimação, estando estas descritas no Quadro 06.

Quadro 06 - Análises do fator legitimação.

\begin{tabular}{|l|l|}
\hline $\begin{array}{l}\text { Fator motivador } \\
\text { legitimação }\end{array}$ & Respostas que reconhecem o fator motivador legitimação \\
\hline $\begin{array}{l}\text { Premissa: organização } \\
\text { busca legitimar sua } \\
\text { atuação através de } \\
\text { parceiros. Legitima sua } \\
\text { participação através da } \\
\text { utilização de normas e } \\
\text { procedimentos aceitos } \\
\text { como suporte e/ou } \\
\text { condutoras de processos } \\
\text { eficientes. }\end{array}$ & $\begin{array}{l}\text { "O pessoal do HACKDAY ajudou validando as regras e } \\
\text { recomendações de conduta do projeto e também produziu } \\
\text { cartilhas de como usar os dados"; }\end{array}$ \\
"Nosso portal foi lançado no Campus Party" e; \\
"Os movimentos livres da sociedade (Transparência Hacker e \\
Open Knowledge Foundation - capítulo BR) iniciaram um \\
processo de diálogo com diversos membros de nosso governo".
\end{tabular}

Fonte: Dados da pesquisa (2016).

Uma das características do fator motivador legitimação é interação com parceiros, com reputação estabelecida, e assim, através dessa parceria legitimar sua participação na rede. Outra característica do fator motivador legitimação é a utilização de normas e procedimentos aceitos como suporte e/ou condutores de processos eficientes. Todos os respondentes afirmaram positivamente quando questionados se os dados disponibilizados atendiam integralmente as recomendações técnicas para dados governamentais abertos. Atender tecnicamente as normas de DGA é uma das formas de legitimar seu projeto, conforme recomendações de entidades como a Open Knowledge Foundation (OKF, 2016).

\subsection{Fatores Facilitadores}

Os aspectos facilitadores dos relacionamentos em redes interorganizacionais podem influenciar o desenvolvimento das atividades nesta rede. Potenciais parceiros (organizações participantes da rede) podem sentir-se mais ou menos atraídos a desenvolver e manter relacionamentos com os demais elementos desta rede, conforme a presença destes aspectos nas relações.

Com relação ao aspecto facilitador "poder", uma organização ao participar de uma rede deve ter claramente identificado seu posicionamento nesta. Para Cox (1999), o poder está relacionado com a capacidade da organização em deter (ser proprietária) de algum recurso 
necessário para os demais participantes da rede. Esta propriedade deve ser capaz de sustentar sua posição e participação na rede.A partir das respostas dos entrevistados foi possível detectar citações ao aspecto facilitador poder, especialmente pela presença da característica posicionamento estratégico, conforme demonstrado no Quadro 07.

Quadro 07 - Análises do fator poder.

\begin{tabular}{|c|c|}
\hline facilitador & Respostas que reconhecem o fator facilitador poder \\
\hline $\begin{array}{l}\text { Premissa: O poder da } \\
\text { organização pode ser } \\
\text { mensurado por } \\
\text { alguns fatores, tais } \\
\text { como sua } \\
\text { independência da } \\
\text { relação com seus } \\
\text { fornecedores e seu } \\
\text { posicionamento } \\
\text { estratégico na rede. }\end{array}$ & $\begin{array}{l}\text { "Existem vários representantes da sociedade civil solicitando dados a } \\
\text { esse órgão"; } \\
\text { "Tornar a informação disponível vai ajudar os próprios órgãos de } \\
\text { governo a terem acesso à base de dados de outros órgãos, de maneira } \\
\text { mais simples. Então, a abertura dos dados é benéfica para dentro do } \\
\text { governo e para/entre o governo e a sociedade"; } \\
\text { "O que pressupõe que os dados sejam colocados em formato aberto, } \\
\text { dentro de um padrão que qualquer um possa utilizar em função dos } \\
\text { softwares de que ele dispõe, sejam livres ou proprietários"; } \\
\text { "Os governos começam a perceber a importância de abrir suas } \\
\text { informações para essa colaboração" e; } \\
\text { "Pode estimular muito essas iniciativas, porque o governo tem muitas } \\
\text { bases de dados, muita informação". }\end{array}$ \\
\hline
\end{tabular}

Fonte: Dados da pesquisa (2016).

Pelas respostas percebe-se que os entrevistados visualizam no recurso "informação", uma característica de posicionamento estratégico, ou seja, governos detêm as informações necessárias para que esta rede se estabeleça e se desenvolva.

Durante as análises das entrevistas não foram encontradas referências ao fator facilitador governança. A característica deste aspecto considerada neste trabalho (Quadro 02) é "quando as organizações buscam resolver eventuais conflitos que possam surgir, especialmente em ambientes complexos". Talvez pelo pouco tempo destes projetos no contexto brasileiro, os participantes ainda não tenham tido a oportunidade de enfrentar conflitos.

O aspecto facilitador "confiança" é descrito neste trabalho (Quadro 02), como "necessária quando o risco, a vulnerabilidade do negócio, é maior que os ganhos econômicos advindos do relacionamento". Esta característica parece adequada a projetos de DGA, pois conforme já discutido nesse artigo existem outras motivações que não somente econômicas para que organizações venham a participar desses projetos. Entre essas e outras motivações podemos citar a exigência de uma maior transparência dos atos dos governos e iniciativas de colaboração entre governos e sociedade visando o desenvolvimento de serviços e/ou aplicativos. 
Em uma boa parte das respostas, diversas inclusive, destacadas durante estas análises, percebe-se referência a termos como "colaboração" e "transparência". Estes termos fazem referência a este fator facilitador, ou seja, existem recompensas - que não são estritamente econômicas - para as organizações que participam destes relacionamentos.

Quanto ao fator facilitador "reputação" sua principal característica considerada para efeito de análise das respostas nesse trabalho é "estabelecer através de uma série de comportamentos, que quanto mais bem-sucedidos as atitudes, melhor a reputação". Segundo definições dos autores de redes interorganizacionais utilizados nesse trabalho a procura por parceiros também pode ser considerada uma forma de buscar reputação.

Quadro 08 - Análises do fator reputação

\begin{tabular}{|l|l|}
\hline $\begin{array}{l}\text { Fator facilitador } \\
\text { reputação }\end{array}$ & Respostas que reconhecem o fator facilitador reputação \\
\hline $\begin{array}{l}\text { Premissa: estabelecida } \\
\text { através de uma série de } \\
\text { comportamentos, } \\
\text { quanto mais bem } \\
\text { sucedidas as atitudes } \\
\text { melhor a reputação e até } \\
\begin{array}{l}\text { mesmo pela procura de } \\
\text { determinados parceiros. }\end{array}\end{array}$ & $\begin{array}{l}\text { "O pessoal do HACKDAY ajudou validando as regras e } \\
\text { recomendações de conduta e também produziu a cartilha de como } \\
\text { usar os dados de nosso projeto"; } \\
\text { "Maior transparência às ações executadas pela/pelo X através da } \\
\text { "Cada vez mais o setor público está respondendo a um anseio da } \\
\text { sociedade que é ter transparência e acesso"; }\end{array}$ \\
\hline
\end{tabular}

Fonte: Dados da pesquisa (2016).

Projetos de dados governamentais abertos estão alicerçados em uma rede de informações, pois este é produto/serviço que viabiliza esta rede. Os governos desenvolvem projetos de DGA para disponibilizar informações, e os demais setores da sociedade buscam usar e/ou interagir através destas informações. Assim, o fator facilitador "troca de informações" é considerado fundamental para que duas ou mais organizações venham a estabelecer um relacionamento, pois uma troca de informações eficiente pode viabilizar outros aspectos relacionais na rede.

Quadro 09 - Análises do fator troca de informações.

\begin{tabular}{|l|l|}
\hline $\begin{array}{l}\text { Fator facilitador } \\
\text { troca de } \\
\text { informações }\end{array}$ & Respostas que reconhecem o fator facilitador troca de informações \\
\hline $\begin{array}{l}\text { Premissa: Uma } \\
\text { eficiente troca de } \\
\text { informações } \\
\text { facilita outros } \\
\text { aspectos como a } \\
\text { confiança e } \\
\text { governança. Este } \\
\text { processo } \\
\begin{array}{l}\text { ocorrendo de } \\
\text { forma eficiente }\end{array}\end{array}$ & $\begin{array}{l}\text { "A disponibilidade de dados abertos vai fazer com que essas coisas se } \\
\text { serão cruzados. Certamente, haverá uma possibilidade real de melhoria } \\
\text { da qualidade desses dados"; }\end{array}$ \\
$\begin{array}{l}\text { "Acredita que o tripé formado por: Governo aberto X Crowdsourcing X } \\
\text { Redes Sociais, pode contribuir positivamente para o desenvolvimento de } \\
\text { produtos/serviços/aplicações na sociedade (para) sociedade, com mais } \\
\text { informações, melhorando a integração desta com os governos"; }\end{array}$ \\
\hline
\end{tabular}


também proporciona melhor utilização de recursos e acesso a mercados e demais parceiros.
"Atualmente o governo $X$ utiliza os serviços de dados abertos do governo $Y$ para atualizar automaticamente os seus sistemas de negócio, assim como o governo $Y$ também utiliza os serviços do governo $X$ com o mesmo propósito";

"Maior transparência às ações executadas através da maior disponibilização das informações produzidas no governo".

O aspecto facilitador "ativos específicos" está relacionado com os possíveis investimentos realizados pelos parceiros para desenvolver e fortalecer as relações. Estes investimentos podem ser materializados de diversas formas, conforme evidenciado no Quadro 02. Quanto mais investimentos forem realizados por um participante da rede, teoricamente este fato irá facilitar a participação dos demais integrantes desta rede. A partir das respostas percebe-se duas iniciativas de investimentos em tecnologia e processos (divulgações, capacitações, entre outros), conforme as respostas transcritas no Quadro 10.

Quadro 10 - Análises do fator ativos específicos.

\begin{tabular}{|c|c|}
\hline $\begin{array}{l}\text { Fat } \\
\text { ativ }\end{array}$ & $\begin{array}{r}\text { Respostas que reconhe } \\
\text { es }\end{array}$ \\
\hline $\begin{array}{l}\text { Premissa: Investimentos } \\
\text { podem ser em tecnologia, } \\
\text { processos, recursos } \\
\text { humanos e outros. }\end{array}$ & $\begin{array}{l}\text { "No final do ano passado foi lançado um concurso para a população } \\
\text { dar ideias para melhorar os serviços na cidade"; } \\
\text { "A API de dados abertos do governo X, está ajudando muitos prefeitos } \\
\text { recém-eleitos a encontrarem convênios de suas prefeituras". }\end{array}$ \\
\hline
\end{tabular}

Fonte: Dados da pesquisa (2016).

Realizando uma análise de ambos os grupos (fatores motivadores e facilitadores), julga-se interessante ressaltar alguns resultados. Com relação aos fatores motivadores pode-se destacar a reciprocidade e a eficiência, como os mais destacados. O fator motivador reciprocidade, citado em diversas respostas, reforça uma das premissas de dados governamentais abertos, ou seja, que estes têm a capacidade de promoverem maior colaboração, pois em sua definição (conforme Quadro 01) consta "está relacionada com a cooperação e/ou colaboração entre as organizações como forma de alcançarem objetivos comuns".

Esta definição de reciprocidade, quando faz referência a "forma de alcançarem objetivos comuns", remete para o próximo fator que é a eficiência, que tem como definição que este fator motiva as organizações a participarem dos relacionamentos de forma que estas venham a alcançar maior eficiência através de uma maior colaboração.

Com relação aos fatores facilitadores pode-se destacar a presença da reputação, esta conforme sua definição (Quadro 02) tem na busca por parceiros afinidade com o fator motivador legitimação, visto que as organizações buscam parcerias visando legitimar sua atuação em setores com outras motivações que não apenas as econômicas. 
Outro resultado que merece especial destaque, pois confirma uma das premissas de DGA, explicitadas no decorrer do artigo, enfatiza que os governos desempenham papel de destaque neste cenário (rede). Este fato é confirmando quando diversos entrevistados reconhecem a posição estratégica dos governos, por estes deterem um recurso estratégico - a informação. Este fato confirma o fator motivador assimetria e o fator facilitador poder.

\section{CONCLUSÕES}

Entende-se que o trabalho atingiu seu objetivo ao permitir identificar quais fatores motivacionais e facilitadores estão presentes em iniciativas de DGA. Esses resultados colaboram para o atendimento da questão problema proposta para o trabalho, pois ao conhecer (ou identificar) esses fatores, pode-se oferecer aos gestores de projetos de DGA, maiores e melhores subsídios para conduzir seus respectivos projetos.

Pode-se concluir que os principais motivadores citados foram: reciprocidade, eficiência e legitimidade. De outra parte, com relação aos fatores facilitadores podemos destacar os fatores: poder, reputação, troca de informações e ativos específicos. Esses fatores ressaltam algumas das características de DGA, tais como: dependência de um setor (governos), ambiente com intensa troca de informações, busca por maior eficiência e, finalmente, fatores que legitimam a reputação, ou seja, por intermédio de DGA os governos reconhecem que podem melhorar sua imagem e relações com a sociedade.

O trabalho contribui com o tema, e seu contexto, ao permitir (revelar) maior conhecimento sobre possíveis motivações e facilitadores apontados pelos gestores públicos, de forma a possibilitar um melhor relacionamento entre governos e sociedade, a partir de pressupostos da teoria das redes interorganizacionais. Conforme explanado durante o trabalho, o conhecimento das motivações e relações nesse contexto (projetos de DGA), ainda, carece de maiores trabalhos que possibilitem um maior entendimento do mesmo.

Como recomendação para futuros trabalhos julga-se pertinente investigar como a sociedade está visualizando os projetos de dados governamentais abertos disponíveis no contexto brasileiro. O fato desse artigo ter abordado a visão dos gestores governamentais, pode ser caracterizada como uma limitação do mesmo. Outra fonte para futuros trabalhos seria comparar a percepção dos gestores governamentais brasileiros com os de outros países.

Estes trabalhos são pertinentes pela importância das redes interorganizacionais e porque projetos de dados governamentais abertos, conforme destacado anteriormente, pressupõe uma ampla interação entre governos e os diversos segmentos da sociedade visando promover mais colaboração, transparência e inovação. Com o reconhecimento que diversos fatores motivacionais e facilitadores, das redes interorganizacionais, estão presentes em projetos de dados 
governamentais abertos, esses resultados demonstram a adequação da teoria das redes interorganizacionais quando aplicadas a iniciativas de DGA.

\section{REFERÊNCIAS}

BALESTRIN, A., VARGAS, L. M. Evidências Teóricas para a Compreensão das Redes Interorganizacionais. In: Encontro de estudos organizacionais, 2., 2002, Recife. Anais... Recife: Observatório da Realidade Organizacional: PROPAD/UFPE: ANPAD, 2002. p. 1-15.

BARDIN, L. Análise de Conteúdo. 9. ed. Lisboa: Editora 70, 2009.

COX, A. Power, value and supply chain management. Supply Chain Management: An International Journal, v. 9, n. 5, p. 167-175, 1999.

COX, A. The art of the possible: relationship management in power regimes and supply chain. Supply Chain Management: An international Journal, v. 9, n. 5, p. 346-356, 2004.

CRESWELL, J. H. Research Design: Qualitative, Quantitative and Mixed Methods Approaches. 3. ed. London: Sage, 2011.

DAWES, S.; HELBIG, N. Open Data and Fitness for Use: A Realistic Look. 2012. Disponível em: <http://www.ctg.albany.edu/publications/issuebriefs/opendata>. Acesso em: 11 out. 2016.

DINIZ, V. Como conseguir dados governamentais abertos. In: Congresso CONSAD de Gestão Pública, 3., 2010, Brasília. Anais... Brasília, 2010. p. 1-19. Disponível em:

<https://i3gov.planejamento.gov.br/como_conseguir_dados_governamentais_abertos.pdf >. Acesso em: 11 out. 2016.

FIORETTI, M. Open Data: Emerging trends, issues and best practices: a research project about openness of public data in EU local admission. [2011]. Disponível em:

<http://www.lem.sssup.it/WPLem/odos/odos_report_2.pdf.> Acesso em: 11 out. 2016.

GOVERNO DO ESTADO DE SÃO PAULO. Governo Aberto SP. Disponível em:

<http://www.governoaberto.sp.gov.br/>. Acesso em: 11 out. 2016.

GRANDORI, A.; SODA, G. Inter-firm Networks: antecedents, mechanisms and forms. Organization Studies, v. 16, n. 2, p. 183-214, 1995.

GURSTEIN, M. Open Data: Empowering the empowered or effective data use for everyone?. First Monday, v. 16, n. 2, 2011. Doi: http://dx.doi.org/10.5210/fm.v16i2.3316.

HAIR JR, J. F. et al. Fundamentos de Métodos de Pesquisa em Administração. Porto Alegre: Bookman, 2005.

HARRISON, T. et al. Delivering Public Value Through Open Government. Albany, USA: Center for Technology in Government (CTG), 2011. Disponível em:

<https://www.ctg.albany.edu/publications/issuebriefs/opengov_pubvalue>. Acesso em: 11 out. 2016.

HELBIG, N. et al. Modeling the Informational Relationships between Government and Society. Center for Technology in Government (CTG): Albany, USA, 2012. Disponível em:

$<$ https://www.ctg.albany.edu/publications/reports/og_workshop_whitepaper/og_workshop_whitepap er.pdf $>$. Acesso em: 11 out. 2016.

JANSSEN, M.; CHARALABIDIS, Y.; ZUIDERWIJK, A. Benefits, Adoption Barriers and Myths of Open Data and Open Government. Information Systems Management (ISM), v. 29, n. 4, p. 258-268, 2012.

KALAMPOKIS, E.; TAMBOURIS, E. A classification scheme for open government data: towards linking decentralized data. International Journal of Web Engineering and Technology, v. 6, n. 3, p. 266-285, 2011. 
HEATH, T.; BIZER, C. Linked Data: Evolving the web into a global data space. Synthesis on the semantic web: theory and technology, Morgan \& Claypool. [2011]. Disponível em: $<$ https://west.unikoblenz.de/files/ws1213/seminar-web-science/linked-data.pdf > Acesso em: 11 out. 2016.

MAZONI, M. V. F. O papel dos dados abertos para seguir construindo um novo Brasil. In: Congresso internacional de software livre e governo eletrônico, 4., 2011, Brasília. Anais... Brasília, 2011. p. 7-9. Disponível em: <http://funag.gov.br/loja/download/817 -

Dados_Abertos_para_a_Democracia_na_Era_Digital.pdf> Acesso em: 11 out. 2016.

MARCON, C.; MOINET, N. Estratégia-rede: ensaio de estratégia. Caxias do Sul: EDUCS, 2001.

OBAMA, B. Transparency and Open Government: memorandum for the head of executive department and agencies. [2009]. Disponível em:

$<$ https://www.whitehouse.gov/the_press_office/TransparencyandOpenGovernment $>$. Acesso em: 11 out. 2016.

OKF. Open Knowledge Foundation. The Open Definition. Disponível em: <http://opendefinition.org/>. Acesso em: 11 out. 2016.

OLIVER, C. Determinants of interorganizational relationships: integration and future directions. The Academy of Management Review, v. 15, n. 2, p. 241-265, 1990.

PARKHE, A. Understanding Trust in International Alliances. Journal of World Business, v. 33, n. 3, p. 219-240, 1998.

PORTER, M. E. What is strategy? Harvard Business Review, v. 74, n. 6, Nov./Dec., p. 61-79, 1996.

PRINCE, A.; JOLÍAS, L.; BRYS, C. Análisis de la cadena de valor del ecosistema de Datos Abiertos de la Ciudad de Buenos Aires. In: Conferencia regional de datos abiertos para américa latina y el caribe, 2013, Montevideo. Anais...Montevideo: [s.n], 2013. p. 1-18. Disponível em:

$<$ https://www.researchgate.net/publication/272168990_Analisis_de_la_cadena_de_valor_del_ecosis tema_de_Datos_Abiertos_de_la_Ciudad_de_Buenos_Aires>. Acesso em: 11 out. 2016.

ROBINSON, D. et al. Government Data and the Invisible Hand.Yale Journal of Law \& Technology, v. 11, n. 1, p.160-175, 2009.

SANTOS, G. D. Estudo Empírico da relação entre Qualidade da Informação e Impacto Individual no Contexto Organizacional. 2009. 258f. Tese (Doutorado em Administração) - Faculdade de Economia, Administração e Contabilidade, Universidade de São Paulo, São Paulo, 2009.

SAMPIERI, R. H.; COLLADO, C. F.; LUCIO, P. B. Metodologia de Pesquisa. 5. ed. Porto Alegre: Penso, 2013. SAPENA, A. F. ; PESET, F.; BENAVENT, R. A. Acesso a Los Datos Públicos y su Reutulización: open data y open government. El profesional de lainformación, v. 20, n. 3, p. 260-269, 2011.

VERGARA, S. C. Método de pesquisa em administração. 6. ed. São Paulo: Atlas, 2005.

W3C. Melhorando o acesso ao governo com o melhor uso da web. [2009]. Disponível em: <http://www.w3c.br/divulgacao/pdf/gov-web.pdf>. Acesso em: 11 out. 2016.

W3C. Manual de Dados Abertos: Governo. [2011]. Disponível em:

$<$ http://www.w3c.br/pub/Materiais/PublicacoesW3C/Manual_Dados_Abertos_WEB.pdf $>$. Acesso em: 11 out. 2016.

WILLIAMSON, O. E. The Economics of Governance. American Economic Review, v. 95, n. 2, p. 1-18, 2005. 